\title{
Using microbial seed coating for improving cowpea productivity under a low-input agricultural system
}

\author{
Inês Rocha, ${ }^{a}{ }^{*}$ Pablo Souza-Alonso, ${ }^{a}$ Graça Pereira, ${ }^{b}$ Ying Ma, ${ }^{a}$ \\ Miroslav Vosátka, ${ }^{c}$ Helena Freitas ${ }^{\mathrm{a}}$ and Rui S. Oliveira ${ }^{\mathrm{a}}$
}

\begin{abstract}
BACKGROUND: Plant-growth-promoting rhizobacteria (PGPR) and arbuscular mycorrhizal (AM) fungi have the ability to enhance the growth, fitness, and quality of various agricultural crops, including cowpea. However, field trials confirming the benefits of microbes in large-scale applications using economically viable and efficient inoculation methods are still scarce. Microbial seed coating has a great potential for large-scale agriculture through the application of reduced amounts of PGPR and AM fungi inocula. Thus, in this study, the impact of seed coating with PGPR, Pseudomonas libanensis TR1 and AM fungus, Rhizophagus irregularis (single or multiple isolates) on grain yield and nutrient content of cowpea under low-input field conditions was evaluated.

RESULTS: Seed coating with $P$. libanensis + multiple isolates of $R$. irregularis (coatPMR) resulted in significant increases in shoot dry weight $(76 \%)$, and in the number of pods and seeds per plant (52\% and $56 \%$, respectively) and grain yield (56\%), when compared with non-inoculated control plants. However, seed coating with $P$. libanensis $+R$. irregularis single-isolate (coatPR) did not influence cowpea grain yield. Grain lipid content was significantly higher $(25 \%)$ in coatPMR plants in comparison with control. Higher soil organic matter and lower pH were observed in the coatPMR treatment.
\end{abstract}

CONCLUSIONS: Our findings indicate that cowpea field productivity can be improved by seed coating with PGPR and multiple AM fungal isolates under low-input agricultural systems.

Keywords: arbuscular mycorrhizal fungi; agricultural sustainability; field experiment; plant growth promoting rhizobacteria

\section{INTRODUCTION}

In recent decades agricultural production has been centered largely on unsustainable inputs of agrochemicals and water. ${ }^{1}$ There is currently a demand for sustainable agricultural practices that safeguard food, air, water, and soil quality, ensuring a safer environment for contemporary and future generations. ${ }^{2}$ Low-input and organic agriculture is consequently gaining worldwide as a way to preserve agro-ecosystem functionality and to reduce economic, environmental, and health costs. ${ }^{3-6}$ The evolution to more sustainable agriculture includes reducing or eliminating the use of non-renewable off-farm anthropoid inputs and giving high importance to the soil and its inhabitants to preserve and maintain ecosystem health. ${ }^{7,8}$

There is currently a great interest in plant-beneficial microbes such as arbuscular mycorrhizal (AM) fungi and plant-growthpromoting rhizobacteria (PGPR), as they play an important role in crop yield improvement and sustainable improvement in agriculture. ${ }^{9}$ Inoculation of AM fungi and PGPR can protect plants against biotic and abiotic stresses and increase the nutritional value of crops in different plant cultivation systems. ${ }^{10}$ Application of these microbes has been considered a key strategy to enhance legume production and quality while reducing the excessive use of chemical fertilizers and pesticides. ${ }^{11-14}$
Cowpea is one of the most important edible grain legumes worldwide with excellent nutritional and nutraceutical properties and it offers several agronomic, environmental, and economic advantages for developed and developing countries. ${ }^{15-17}$ Enhancement of biomass, grain yield, and nutrient content in cowpea inoculated with AM fungi and PGPR has been demonstrated previously. ${ }^{18,19}$ Yet, the lack of efficient inoculation methods for these microbes is a constraint for their large-scale application.

Broadcasting of inocula of AM fungi and PGPR in open agricultural fields can be costly. ${ }^{20,21}$ Seed coating is considered a viable tool for precise and broad delivery of AM fungi and PGPR to

\footnotetext{
* Correspondence to:IRocha, Centre for Functional Ecology-Science for People \& the Planet, Department of Life Sciences, University of Coimbra, Calçada Martim de Freitas, 3000-456 Coimbra, Portugal. E-mail: ines.sousa.rocha@uc.pt

a Centre for Functional Ecology - Science for People and the Planet, Department of Life Sciences, University of Coimbra, Coimbra, Portugal

b Biotechnology and Genetic Resources Unit, National Institute for Agrarian and Veterinary Research, Elvas, Portugal

c Czech Academy of Sciences, Institute of Botany, Prühonice, Czech Republic
} 
different agricultural crops, and it has been explored in cowpeas under greenhouse conditions. ${ }^{22,23}$ This inoculation method allows the application of low amounts of inocula in combination with other exogenous ingredients onto the seed surface, resulting in close plant-microbe contact at the early plant development stage. Despite studies showing the excellent potential of AM fungi to enhance the nutritional status and productivity of various crops $^{24-27}$ the application of AM fungi (single or in consortia) via seed coating is still rare.

Moreover, although greenhouse experiments provide important and useful data regarding the benefits of microbial inoculation, the validation of microbial effects under field conditions across a range of environments is required. ${ }^{28}$ In fact, the lack of consistency in field performance can be a major constraint on the wider use of microbial seed coating. ${ }^{9,29}$ The aim of the present study was to evaluate the effects of seed coating with the PGPR Pseudomonas libanensis and the AM fungus Rhizophagus irregularis (single or multiple isolates) on cowpea productivity under low-input field conditions. We hypothesized that inoculation of multiple AM fungal isolates + PGPR results in superior cowpea performance when compared to single AM fungal isolate + PGPR or no inoculation under field conditions.

\section{MATERIALS AND METHODS}

\section{Seeds, microbial inocula and coating}

The seeds of cowpea, Vigna unguiculata (L.) Walp. Cv. Fradel, used in this study were obtained from the collection of the National Institute for Agrarian and Veterinary Research (INIAV). Pseudomonas libanensis TR1 (GenBank accession no. KR051238), previously isolated from Trifolium repens rhizosphere existing in serpentine soils in Bragança (Portugal), was obtained from the collection of the Center for Functional Ecology, University of Coimbra. ${ }^{30}$ Pseudomonas libanensis TR1 exhibited tolerance to heat $\left(38^{\circ} \mathrm{C}\right)$, salinity $(8 \%)$ and severe drought $(-1.5 \mathrm{Mpa})$ and it was tested positively for 1-aminocyclopropane-1-carboxylate (ACC) deaminase, indoleacetic acid (IAA), siderophores and ammonia production, phosphate solubilization, and $\mathrm{N}$ fixation. ${ }^{22}$ To prepare the inoculum for seed coating, the bacterial strain was grown in Luria Bertani media overnight at $28-30^{\circ} \mathrm{C}$ and 200 revolutions per minute, according to Ma et al. ${ }^{30}$ Two different AM fungal inocula were used: (i) a single fungal isolate of $R$. irregularis (BEG140) and (ii) a mixture of $R$. irregularis isolates (BEG141, BEG236, DAOM 197198, KW and AS). Previously, all AM fungi inocula (provided by Symbiom Ltd, Czech Republic) were grown for 8 months with Zea mays L. as host plant, in a multispore pot culture with 1:1 (v/v) of zeolite and expanded clay. The AMF inocula were cultivated as single isolate cultures and then equal parts of inocula were mixed to prepare the $R$. irregularis mixture.

For seed-coating inoculation, cowpea seeds were previously immersed (for $45 \mathrm{~min}$ ) in a P. libanensis solution with a concentration of $10^{7}$ colony-forming units (CFU) $\mathrm{mL}^{-1}$, then air-dried and dressed using a rotating pan. ${ }^{31}$ Cowpea seeds were first dusted with sieved $(500 \mu \mathrm{m}) R$. irregularis inoculum and secondly with biochar ( $0.25 \%$ per seed weight) (Ecochar, Ibero Massa Florestal, Portugal), using a sticker solution of $2 \%$ gum arabic. Twenty AM fungal propagules were applied per seed (for both inocula), estimated according to the most probable number method. ${ }^{32}$ After coating, the final bacterial concentration was $10^{6} \mathrm{CFU}$ per coated seed. The CFU was estimated as described in Rocha et al. ${ }^{27}$

\section{Field experimental conditions and design}

The experiment was conducted in an agricultural field located in Elvas, Portugal ( $\left.38^{\circ} 53^{\prime} 16.3^{\prime \prime} \mathrm{N}, 7^{\circ} 08^{\prime} 16.8^{\prime \prime} \mathrm{W}\right)$, between June and September 2018. The soil had a clay texture and presented the following properties: $0.40 \mathrm{mS} \mathrm{cm}^{-1}$ electrical conductivity, $8.1 \mathrm{pH}$ (1:2.5 w/v water), $1.1 \%$ organic matter, $0.08 \%$ nitrogen (N) (Kjeldahl method), $>200 \mathrm{mg} \mathrm{kg}^{-1}$ extractable (Egner-Riehm method) phosphorus (P), $138 \mathrm{mg} \mathrm{kg}^{-1}$ extractable (Egner-Riehm method) potassium (K), $2768 \mathrm{mg} \mathrm{kg}^{-1}$ extractable (ammonium acetate) calcium, and $417 \mathrm{mg} \mathrm{kg}^{-1}$ extractable (ammonium acetate) magnesium. The field is used for cowpea and cereals (i.e. wheat and triticale) production in a crop rotation system. The site had been uncultivated for 1 year before the beginning of the field experiment. The experimental design was based on three dissimilar inoculations: (i) non-coated / non-inoculated seeds, control; (ii) coated seeds with P. libanensis + R. irregularis BEG140, coatPR; and (iii) coated seeds with P. libanensis + the mixture of $R$. irregularis and coatPMR described above. The experimental plot consisted of two rows of $3 \mathrm{~m}$ (with 10 seeds each and spaced at a distance of $60 \mathrm{~cm}$ ) in a total of three repetitions per treatment set, organized in a split-plot randomized block. Seeds from different inoculation treatments were sown manually at $2-3 \mathrm{~cm}$ depth. No synthetic components were added to the soil (i.e. fertilizers or pesticides) before or during the experiment. Watering was done twice a week during $2 \mathrm{~h}$ to avoid water stress using a drip irrigation system. During the experiment the temperature, relative humidity and precipitation ranged from 13 to $26^{\circ} \mathrm{C}, 42$ to $78 \%$ and 0 to $8 \mathrm{~mm}$, respectively.

\section{Plant, soil, and grain analyses}

Approximately 83 days after sowing (DAS) cowpea was harvested. Data regarding DAS to flowering (50\% of the plants flowering) and maturity (maturity of $50 \%$ of the plants) were collected. The numbers of pods and seeds per plant were counted. Seeds were weighed and plant shoots dried at $70^{\circ} \mathrm{C}$ for $48 \mathrm{~h}$ and weighed. The grain yield $\left(\mathrm{kg} \mathrm{ha}^{-1}\right)$, weight of 100 seeds (average of 300 seeds from each treatment), and harvest index (the ratio of seed weight to shoot dry weight) were calculated.

At plant harvest, samples of the rhizosphere soil from the different treatments were collected and analyzed for $\mathrm{pH}(1: 5 \mathrm{v} / \mathrm{v})$, organic matter (dry combustion at $590^{\circ} \mathrm{C}$ ), N (Kjeldahl method), $\mathrm{P}$ (Egner-Riehm method), and $\mathrm{K}$ (Egner-Riehm method) content. Samples of cowpea grains were dried $\left(70^{\circ} \mathrm{C}\right.$ for $\left.48 \mathrm{~h}\right)$, finely ground and used to determine crude protein, fiber, fat, and ash content. Crude protein was analyzed by the Kjeldahl method according to the international standard ISO 20 483:2006 and the protein was calculated as $\mathrm{N}_{\text {content }} \times 6.25$. Crude fiber content was obtained using the ratio between the reduction in mass resulting from ashing of the dried digestion grain residue (acid and alkaline digestion) and the mass of the test sample, according to the method of intermediate filtration from the Portuguese norm (NP) ISO 6865:2009. The determination of grain fat content was carried out using the Soxtec System HT1043 extraction apparatus with ether ethylic (NP 876:2001). The ash yield was obtained by the ratio between the difference in the mass of the ashing dish and incinerated grain residue, divided by the mass of the test sample (ISO 2171:2007).

\section{Mycorrhizal root colonization}

Roots were separated from shoots, washed, cut into $1 \mathrm{~cm}$ pieces, and stained in a trypan blue solution in accordance with a modified Phillips and Hayman ${ }^{33}$ protocol. ${ }^{34}$ The grid-line intersect method ${ }^{35}$ 
was used to estimate the percentage of root length colonized (RLC) through observation of stained roots under a stereomicroscope (Leica EZ4 HD, Germany).

\section{Bacterial detection in cowpea rhizosphere}

During harvest, plants were gently uprooted and $2 \mathrm{~g}$ of soil firmly adhered to roots (considered as rhizosphere soil) was collected and kept in plastic bags. Bags were labeled and maintained in cold conditions $\left(4^{\circ} \mathrm{C}\right)$ during transport to the laboratory, where they were frozen at $-20^{\circ} \mathrm{C}$. About $0.25 \mathrm{~g}$ of soil was used for DNA extraction using the NucleoSpin ${ }^{\circledR}$ soil extraction kit (Macherey-Nagel, Germany). Extracted DNA was stored at $-20^{\circ} \mathrm{C}$. DNA purity was verified through absorbance (A260/A280) using a UV-visible spectrophotometer (NanoVue Plus, Biochrom, England). The presence of bacterial DNA was verified by amplification with the general primer pair 27f (5'-AGAGTTTGATCCTGGCTCAG-3') and 1492r (5'-GGTTACCTTGTTACGACTT- $\left.3^{\prime}\right){ }^{36}$ targeted at the $16 \mathrm{~S}$ rRNA of eubacteria. The reaction mix contained $2.5 \mu \mathrm{mol} \mathrm{L}^{-1}$ of each primer, $12.5 \mu \mathrm{L}$ of DSF Taq Master Mix (BIORON, Germany) $(2.5 \mu \mathrm{L}$ of buffer, $200 \mu \mathrm{mol} \mathrm{L}^{-1}$ of dNTPs, $0.5 \mathrm{U}$ of DFS-Taq polimerase), and $1 \mu \mathrm{L}$ of template DNA in a final volume of $25 \mu \mathrm{L}$. A rapid amplification cycle was carried out with the following conditions: an initial denaturation step of $2 \mathrm{~min}$ at $95^{\circ} \mathrm{C}$, followed by 25 cycles of $20 \mathrm{~s}$ at $94^{\circ} \mathrm{C}, 30 \mathrm{~s}$ at $57^{\circ} \mathrm{C}$, and $1 \mathrm{~min}$ at $72^{\circ} \mathrm{C}$, with a final extension step of $10 \mathrm{~min}$ at $72^{\circ} \mathrm{C}$.

Once the presence of bacteria was positively confirmed, the presence of $P$. libanensis TR1 in cowpea rhizosphere was studied using a nested-Polymerase chain reaction (PCR) approach. Initially, the specific primer pair GyrBF (5'-AGCATCAAGGTGCTGAAAGG-3') GyrBR (5'-GGTCATGATGATGATGTTGTG-3'), targeted at the gyrB gene, ${ }^{37}$ was used to detect the presence of Pseudomonas using the following PCR conditions: an initial denaturation step of $5 \mathrm{~min}$ at $94^{\circ} \mathrm{C}$, followed by 35 cycles of $30 \mathrm{~s}$ at $94^{\circ} \mathrm{C}, 30 \mathrm{~s}$ at $57^{\circ} \mathrm{C}$, and $1 \mathrm{~min}$ at $72^{\circ} \mathrm{C}$, with a final extension step of $5 \mathrm{~min}$ at $72^{\circ} \mathrm{C}$. Reaction mix contained $2.5 \mu \mathrm{mol} \mathrm{L}^{-1}$ of each primer, $12.5 \mu \mathrm{L}$ of DSF Taq Master Mix (BIORON) (2.5 $\mu \mathrm{L}$ of buffer, $200 \mu \mathrm{mol} \mathrm{L}^{-1}$ of dNTPs, $0.5 \mathrm{U}$ of DFS-Taq polimerase), and $1 \mu \mathrm{L}$ of template DNA. Amplification produced a PCR product of approximately $1460 \mathrm{bp}$ that was used for the specific identification of our strain. On the basis of the nucleotide sequence of the GyrB gene of $P$. libanensis TR1, we designed a set of specific primers targeted to unique regions within this sequence (Souza-Alonso etal., in preparation). In this study, two primer pairs designed to amplify specific regions of our strain were tested, including PsTR1aFor (5'-CGACGACATCAGCATTATCA-3') and PsTR1bRev (5'-CAGTGAGGATCAGTTCTTCG-3'), as well as PsTR1aFor (5'-CGACGACATCAGCATTATCA-3') and PsTR1cRev (5'CGGACAGTGAGGATCAGTTC- $\left.3^{\prime}\right)$. The PCR products $(5 \mu \mathrm{L})$ of the first round were further used for the nested-PCR using specific primers. In this case, reaction mix contained $2.5 \mu \mathrm{mol} \mathrm{L}^{-1}$ of each primer, $10 \mu \mathrm{L}$ of DSF Taq Master Mix (BIORON) (2.5 $\mu \mathrm{L}$ of buffer, $200 \mu \mathrm{mol} \mathrm{L}^{-1}$ of dNTPs, $0.5 \mathrm{U}$ of DFS-Taq polimerase), and $5 \mu \mathrm{L}$ of amplified DNA (using GyrB primers) as template. In both cases, amplification conditions were as follows: an initial denaturation step of $5 \mathrm{~min}$ at $95^{\circ} \mathrm{C}$, followed by 30 cycles of $30 \mathrm{~s}$ at $95^{\circ} \mathrm{C}, 45 \mathrm{~s}$ at $52^{\circ} \mathrm{C}$, and $30 \mathrm{~s}$ at $72^{\circ} \mathrm{C}$, with a final extension step of $5 \mathrm{~min}$ at $72{ }^{\circ} \mathrm{C}$.

In all cases, $5 \mu \mathrm{L}$ of the obtained PCR products was analyzed using agarose (1\%) gel electrophoresis stained with GreenSafe Premium (NZYTech, Portugal). DNA extracted from pure culture of $P$. libanensis TR1 served as positive control. Amplified DNA was visualized by GelDoc ${ }^{\mathrm{TM}} \mathrm{XR}+$ system with the Image Lab software (2.0.1, BIO-RAD, California, United States).

\section{Statistical analysis}

Data were analyzed using one-way analysis of variance (ANOVA) for each dependent variable versus the independent variable (inoculation), when normality and homogeneity of variances were confirmed. Duncan's multiple-range test was use to compare treatment means, when F-values were significant $(P<0.05)$. When normality assumptions of parametric tests were not met, differences between groups of data were tested for significance using a non-parametric Kruskal-Wallis test with a sequential Bonferroni correction for multiple comparisons, at $\alpha=0.05 / \mathrm{n}$ with $\mathrm{n}$ the number of pairwise comparisons. All statistical analyses were carried out using the IBM SPSS Statistics 25.0 software package (IBM SPSS Inc., Chicago, IL, USA).

\section{RESULTS}

Seed coating did not hinder cowpea germination. Seeds took approximately 6 DAS to germinate, 50 DAS to flowering, and 69 DAS to maturation, showing no significant differences between the different treatments.

\section{Cowpea productivity and grain quality}

In general, seed coating with $P$. libanensis and a mixture of $R$. irregularis isolates (CoatPMR) increased cowpea productivity when compared with the control treatment (Table 1). The coatPMR treatment showed a significant increase of $76 \%$ in shoot dry weight, $52 \%$ in the number of pods, $56 \%$ in the number of seeds per plant and grain yield. No differences were obtained in the weight of 100 seeds among treatments.

CoatPR treatment had a negative influence on individual seed weight when compared with control and CoatPMR, and lower harvest index percentage, comparing to CoatPMR (Table 1 and Fig. 1). A summary of cowpea harvesting productivity parameters among the different treatments is presented in Fig. 2.

Protein and crude fiber grain contents were not influenced by microbial coating (Table 2). Fat content was significantly higher in

Table 1. Growth and productivity parameters of cowpea in different treatments: control, Pseudomonas libanensis + Rhizophagus irregularis (coatPR), $P$. libanensis + mixture of $R$. irregularis (coatPMR) under field conditions

\begin{tabular}{lcccccc} 
Treatment & $\begin{array}{c}\text { Shoot dry } \\
\text { weight }(\mathrm{g})\end{array}$ & $\begin{array}{c}\text { Number of pods } \\
\text { per plant }\end{array}$ & $\begin{array}{c}\text { Number of seeds } \\
\text { per plant }\end{array}$ & $\begin{array}{c}\text { Weight of individual } \\
\text { seeds per plant }(\mathrm{g})\end{array}$ & $\begin{array}{c}\text { Weight of } 100 \\
\text { seeds }(\mathrm{g})\end{array}$ & $\begin{array}{c}\text { Grain yield } \\
(\mathrm{kg} \mathrm{ha})\end{array}$ \\
\hline Control & $23.7 \pm 2.9^{\mathrm{a}}$ & $34.2 \pm 3.9^{\mathrm{a}}$ & $254.6 \pm 28.9^{\mathrm{a}}$ & $0.18 \pm 0.003^{\mathrm{b}}$ & $18.5 \pm 0.3$ & $2537.2^{\mathrm{a}}$ \\
CoatPR & $31.2 \pm 3.3^{\mathrm{ab}}$ & $34.6 \pm 3.2^{\mathrm{a}}$ & $264.5 \pm 26.9^{\mathrm{a}}$ & $0.17 \pm 0.004^{\mathrm{a}}$ & $18.8 \pm 0.4$ & $2489.3^{\mathrm{a}}$ \\
CoatPMR & $41.5 \pm 4.8^{\mathrm{b}}$ & $52.1 \pm 5.0^{\mathrm{b}}$ & $396.1 \pm 25.7^{\mathrm{b}}$ & $0.18 \pm 0.004^{\mathrm{b}}$ & $19.3 \pm 0.3$ & $3952.2^{\mathrm{b}}$ \\
\hline
\end{tabular}

Mean ( \pm SE) followed by letters that indicate significant differences between treatments according to Duncan's multiple range test at $P<0.05$. 


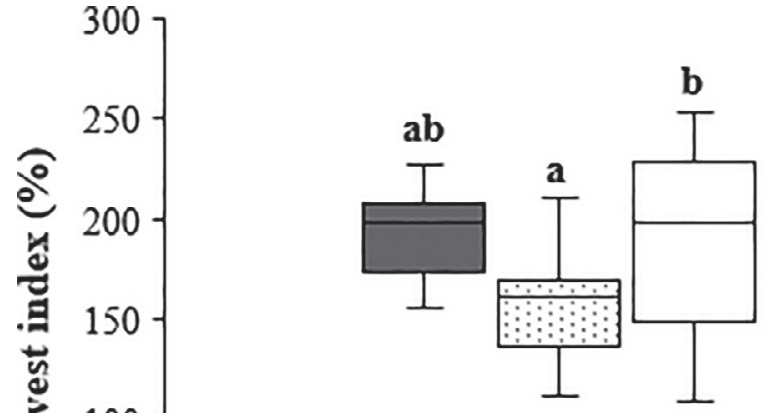 \\ $\square$ Control $\square$ CoatPR $\square$ CoatPMR}

Figure 1. Harvest index (ratio of seeds to shoot dry weight) of cowpea with different inoculation treatments: control, Pseudomonas libanensis + Rhizophagus irregularis (coatPR), P. libanensis + mixture of $R$. irregularis (coatPMR).

seeds of coatPMR treatment in comparison to control and coatPR treatments. Ash content increased $6 \%$ in plants from the coatPR treatment.

\section{Soil physicochemical properties}

Soil organic matter (SOM) and $\mathrm{pH}$ (Table 3) were significantly influenced by coatPMR inoculation. In terms of SOM, the values were higher in CoatPMR when compared with the control. pH was lower in CoatPMR than that in control and coatPR. Both P and $\mathrm{K}$ had similar concentrations among different treatments.

\section{Microbial colonization}

Mycorrhizal colonization was significantly lower in coatPMR plants, which had a RLC of $29 \%$, a substantial reduction in comparison
Table 2. Cowpea grain content in different inoculation treatments: control, Pseudomonas libanensis + Rhizophagus irregularis (coatPR), P. libanensis and a mixture of $R$. irregularis isolates (coatPMR)

\begin{tabular}{lcccc} 
Treatment & $\begin{array}{c}\text { Crude } \\
\text { protein (\%) }\end{array}$ & Fat (\%) & $\begin{array}{c}\text { Crude } \\
\text { fiber (\%) }\end{array}$ & Ash (\%) \\
\hline Control & $20.8 \pm 0.3$ & $1.0 \pm 0.03^{\mathrm{a}}$ & $3.8 \pm 0.1$ & $3.2 \pm 0.05^{\mathrm{a}}$ \\
CoatPR & $20.8 \pm 0.5$ & $1.1 \pm 0.04^{\mathrm{a}}$ & $3.9 \pm 0.1$ & $3.4 \pm 0.06^{\mathrm{b}}$ \\
CoatPMR & $21.1 \pm 0.4$ & $1.3 \pm 0.02^{\mathrm{b}}$ & $3.7 \pm 0.1$ & $3.2 \pm 0.05^{\mathrm{a}}$ \\
\hline
\end{tabular}

Mean $( \pm$ SE) followed by letters that indicate significant differences between treatments according to Duncan's multiple range test and Kruskal-Wallis test at $P<0.05$.

with the $41 \%$ of colonization observed in control roots (Fig. 3). Although coatPR treatment also showed a reduced percentage of RLC (37\%), in this case the difference was not significant. After 83 days of plant growth, the presence of $P$. libanensis TR1 could not be confirmed in the roots and rhizosphere of coated cowpea. The presence of general bacteria and the Pseudomonas genus were positively confirmed in cowpea rhizosphere by PCR detection using general primers (27f-1492r and GyrBF-GyrBR). However, the use of specific primers did not evidence the presence of our strain by the end of the assay.

\section{DISCUSSION}

Previous greenhouse studies reported benefits from AM fungi and PGPR, either inoculated by the conventional method (direct application in the soil) ${ }^{21,38-40}$ or through seed coating ${ }^{23}$ in cowpea performance. Nevertheless, there is still lack of information on the effect of AM fungi and PGPR, which can represent a significant barrier to up-scale microbial applications. ${ }^{29,41}$ According to Malusà et al., ${ }^{13}$ consortia of beneficial microbes can be more efficient than single-strain inoculants, due to the combination of various mechanisms of action of the different microorganisms present. In the field, plant global response should be considered multi-factorial and so versatile consortia of microbes that harbor

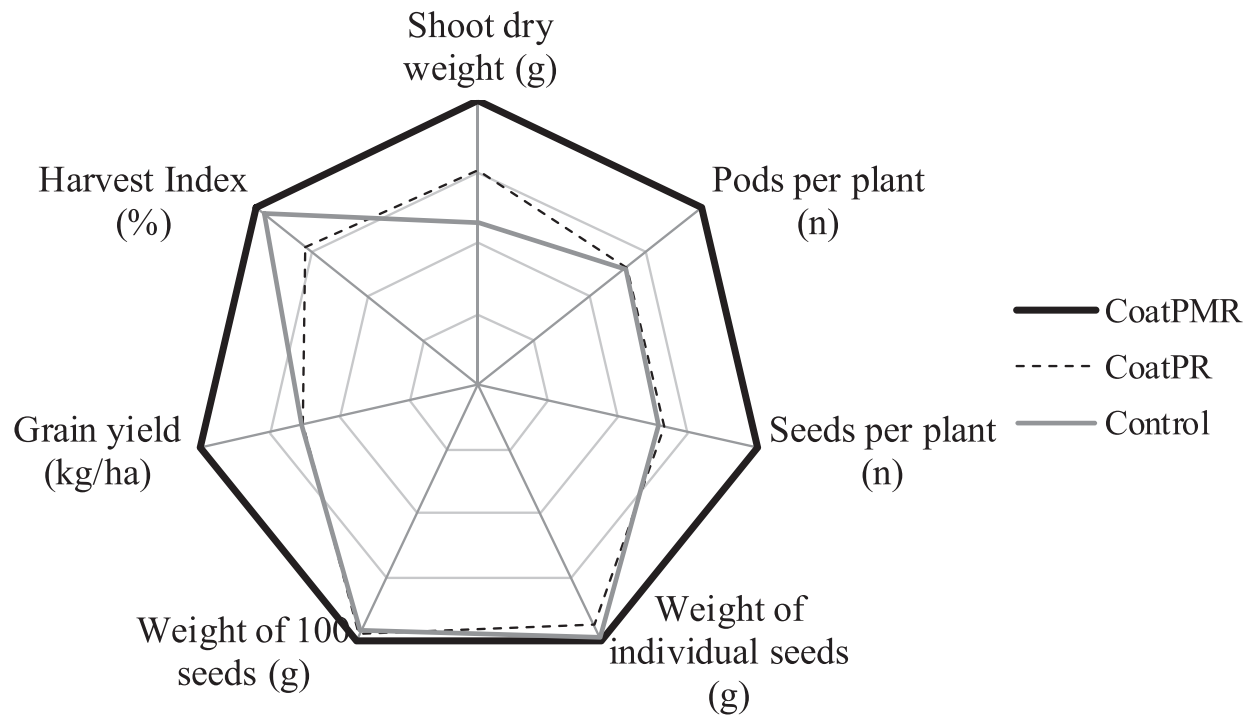

Figure 2. Harvesting productivity parameters of cowpea in different inoculation treatments: control, coated with Pseudomonas libanensis + Rhizophagus irregularis (coatPR) or coated with P. libanensis + a mixture of different $R$. irregularis isolates (coatPMR). Radial graphs represent results relative to the higher value (indicated as $100 \%$ ) for each productivity parameter. 
Table 3. Soil physicochemical properties after plant growth

\begin{tabular}{lccccc} 
Treatment & $\mathrm{pH}\left(\mathrm{H}_{2} \mathrm{O}\right)$ & $\mathrm{SOM}(\%)$ & $\mathrm{N}(\%)$ & $\mathrm{P}\left(\mathrm{mg} \mathrm{P}_{2} \mathrm{O}_{5} \mathrm{~kg}^{-1}\right)$ & $\mathrm{K}\left(\mathrm{mg} \mathrm{K}_{2} \mathrm{O} \mathrm{kg}{ }^{-1}\right)$ \\
\hline Control & $8.2 \pm 0.03^{\mathrm{a}}$ & $0.8 \pm 0.06^{\mathrm{a}}$ & $0.07 \pm 0.00$ & $358 \pm 27$ & $175 \pm 3$ \\
CoatPR & $8.2 \pm 0.03^{\mathrm{a}}$ & $0.9 \pm 0.03^{\mathrm{ab}}$ & $0.08 \pm 0.03$ & $354 \pm 11$ & $166 \pm 1$ \\
CoatPMR & $8.1 \pm 0.00^{\mathrm{b}}$ & $1.1 \pm 0.00^{\mathrm{b}}$ & $0.08 \pm 0.03$ & $355 \pm 5$ & $173 \pm 4$ \\
\hline
\end{tabular}

Mean $( \pm$ SE) followed by letters that indicate significant differences between treatments according to Duncan's multiple range test and Kruskal-Wallis test at $P<0.05$. CoatPR (Pseudomonas libanensis + Rhizophagus irregularis), coatPMR ( $P$. libanensis + mixture of $R$. irregularis isolates), nitrogen (N), soil organic matter (SOM), phosphorus (P) and potassium (K).

different characteristics can complement each other and become more functional. Yet, host specificity of microbial strains and growing conditions (e.g. soil properties, native microbiota, nutrition) can greatly affect the efficacy of beneficial microbes in improving the productivity of agricultural crops. ${ }^{5}$ In our study, coating with $P$. libanensis + multiple isolates of $R$. irregularis showed maximum cowpea growth and yield among treatments, while $P$. libanensis $+R$. irregularis single-isolate coating did not bring any advantage to cowpea performance. Despite having the same shoot biomass, plants from coatPR treatment produced fewer seeds than control, resulting in a lower harvest index. The absence of beneficial effects of co-inoculation of $P$. libanensis $+R$. irregularis BEG140 coated onto cowpea seeds has already been shown in a greenhouse trial conducted by Ma et al. ${ }^{22}$ In the study, improvement in plant growth was only observed when $P$. libanensis was inoculated alone. Inoculation of a consortium of $P$. libanensis and $R$. irregularis showed no growth improvement in cowpea. Further research is required to evaluate which AM fungal isolates in the treatment coatPMR were active and benefited cowpea, as well as the role of PGPR in the consortium.

An estimation of the production cost of seed coating with microbial inoculants and the grain yield obtained in our study showed that choosing the right inoculum is crucial to obtain substantial profits for the farmer. Considering the producer price of chickpea in the USA as $0.824 \mathrm{USD} / \mathrm{kg}^{42}$ and the cost of seed coating as 154.67 USD/ha (estimation from the price of inocula and seed coating procedure, including coating materials and labor) the obtained profit for the farmer would be of 2090.65, 1896.13, and 3101.56 USD/ha for the control treatment, PRcoat and PMRcoat, respectively. This corresponds to an increase of $48 \%$ in profit brought by the use of seeds coated with the mixture of $R$. irregularis isolates.

Besides yield and growth promotion, PGPR and AM fungi can improve the nutritional quality of leaves, fruits or seeds of different crops, ${ }^{43-45}$ and soil properties. ${ }^{9,46}$ In our study, lipid content and ash were increased by coatPMR and coatPR, respectively. Soil physicochemical properties were slightly modified after the growth of plants inoculated with $P$. libanensis + multiple AM fungi isolates. After plant harvest, soil $\mathrm{pH}$ was slightly reduced ( 0.1 units) and SOM experienced a significant increase (37.5\%) when compared with the control. Microbial activity can decrease the rhizosphere $\mathrm{pH}$ of inoculated plants and lead to the production of root exudates, which can increase SOM. ${ }^{47}$ It is well known that soil parameters such as SOM and $\mathrm{pH}$ strongly affect soil functions and nutrient bioavailability. ${ }^{48,49}$ Soil organic matter contributes significantly to improving soil structure and aggregation, soil fertility, water retention, and soil biodiversity. Usually, increases in SOM correspond to higher plant productivity. ${ }^{50}$ The influence of inoculation of $P$. libanensis + multiple AM fungi isolates in soil

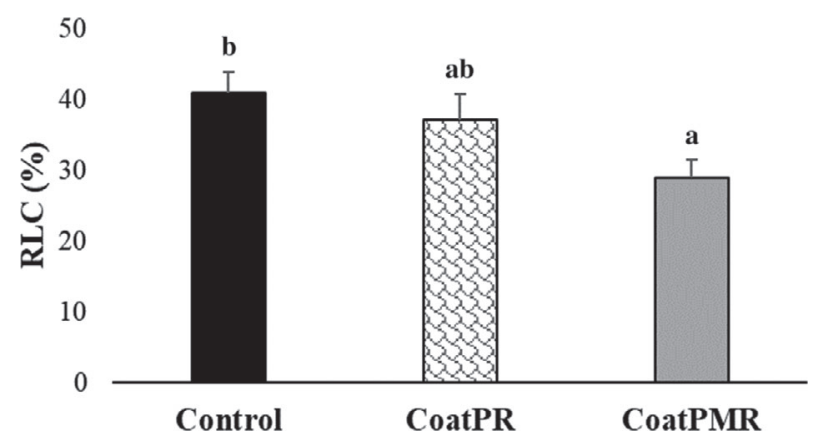

Figure 3. Mycorrhizal colonization, expressed as percentage of root length colonization (\% RLC) in the roots of cowpea non-inoculated (control) and inoculated with Pseudomonas libanensis + Rhizophagus irregularis BEG140 (coatPR) or $P$. libanensis + mixture of $R$. irregularis BEG141, BEG236, DAOM $197198, \mathrm{KW}$ and AS (coatPMR) via seed coating. Columns are means $\pm 1 \mathrm{SE}$ and letters indicate significant differences $(P<0.05)$ according to Duncan's multiple range test.

physicochemical properties may have helped to increase cowpea productivity.

High levels of AM fungi root colonization do not always correspond with an excellent crop yield. ${ }^{28,51}$ Inoculation with AM fungi can significantly influence (by promoting or hampering) the development of rhizobacteria and other fungi in plant roots and rhizosphere soils. ${ }^{5,52}$ Our results showed that cowpea coated with $P$. libanensis + multiple isolates of AM fungi had the highest productivity but the lowest mycorrhizal root colonization. Interspecific competition possibly decreased the presence of native AM fungi, reducing overall colonization in cowpea roots. Arbuscular mycorrhizal colonization can be highly dependent on its host and in the symbiotic relationship plants can mediate competition to favor high-quality interactions..$^{53}$ By providing different amounts of resources to fungal species, plants can affect the outcome of fungal competition. ${ }^{54,55}$ For instance, Bever et al. ${ }^{56}$ showed that plants could allocate resources in their roots in a selective way, giving preference and supporting the fungal species that provide more nutrients. Thus, either AM fungi mixture was more competitive than native AM fungi or a specific AM fungal isolate presented better host specificity with cowpea, thereby prevailing over native. Consequently, it is possible that the reduction in the extent of mycorrhizal root colonization resulted in lower carbon cost for the host plant and thus improved plant yield. According to Janoušková et $a . .^{57}$ inoculation may substantially decrease the diversity of the root-colonizing AM fungal community by suppressing root colonization by native AMF, which can possibly explain the lower root colonization in the coatPMR treated plants.

The presence of $P$. libanensis TR1 in the roots and rhizosphere of cowpea was not confirmed at the end of the field experiment. The PGPR colonization in the roots and rhizosphere of host plants 
can decline from high concentrations to low in a short time, ${ }^{58}$ depending on plant species. ${ }^{59}$ After being inoculated, bacteria can successfully colonize roots, yet their concentrations frequently decline rapidly due to competition with native microorganisms and / or predation by protozoa and nematodes. It is possible that 83 days after sowing (harvest time) the concentration of bacteria was too low to be detected with the methodology used. Nevertheless, the absence of the inoculated bacterial strain does not necessarily imply the absence of its effects, as demonstrated by Rosas et al., ${ }^{60}$ who found that the concentration of the inoculated Pseudomonas aurantiaca can decrease over time in the rhizosphere, with benefits in plant growth during the entire cycle of the crop.

\section{CONCLUSIONS}

In this study, results indicate that seed coating with multiple AM fungal isolates and PGPR can be a promising tool to enhance cowpea productivity under field conditions, depending on the combination of beneficial microbes. Seed coating of multiple AM fungal isolates $+P$. libanensis improved cowpea productivity and seed quality in the field, when compared with non-inoculated plants. Apart from the increase in grain ash content, inoculation of single $R$. irregularis $+P$. libanensis did not influence cowpea performance, indicating that the right microbial combination is essential to achieve improved crop productivity. Substantial profit for farmers can be obtained through seed coating of cowpea with effective consortia of beneficial microbes. Seed coating can be a valid approach to deliver beneficial microbes into low-input and sustainable agricultural systems, aiming at improving soil properties, grain yield, and quality.

\section{ACKNOWLEDGEMENTS}

I. Rocha acknowledges the support of the Portuguese Foundation for Science and Technology (FCT) through the research grants SFRH/BD/100484/2014, the European Social Fund and Programa Operacional do Capital Humano (POCH). This work was supported by the European Structural and Investment Funds in the FEDER component, through the Operational Competitiveness and Internationalisation Programme (COMPETE 2020) (Project No. 016801 (PTDC/AGR-TEC/1140/2014); Funding Reference: POCl-01-0145-FEDER-016801); and national funds through the FCT - Portuguese Foundation for Science and Technology under the Project PTDC/AGR-TEC/1140/2014. The authors thank José Eduardo Moreira, Beatriz Quintas, and Ana Sofia Bagulho for help with the field experiments.

\section{REFERENCES}

1 More people FAO and food $\mathrm{m}$, in Worse Water?: A Global Review of Water Pollution from Agriculture, ed. by Mateo-Sagasta J, Zadeh SM, Turral $\mathrm{H}$ and Rome I. International Water Management Institute (IWMI). CGIAR Research Program on Water, Land and Ecosystems (WLE), FAO Colombo, Sri Lanka (2018).

2 Patil S, Reidsma P, Shah P, Purushothaman S and Wolf J, Comparing conventional and organic agriculture in Karnataka, India: where and when can organic farming be sustainable? Land Use Policy 37:40-51 (2014).

3 Crowder DW, Northfield TD, Strand MR and Snyder WE, Organic agriculture promotes evenness and natural pest control. Nature 466:109-112 (2010).

4 Postma-Blaauw MB, de Goede RGM, Bloem J, Faber JH and Brussaard L, Soil biota community structure and abundance under agricultural intensification and extensification. Ecology 91:460-473 (2010).
5 Pellegrino E and Bedini S, Enhancing ecosystem services in sustainable agriculture: biofertilization and biofortification of chickpea (Cicer arietinum L.) by arbuscular mycorrhizal fungi. Soil Biol Biochem 68:429-439 (2014).

6 Reganold JP and Wachter JM, Organic agriculture in the twenty-first century. Nat Plants 2:15221(2016).

7 Gliessman SR, Agroecology and agroecosystems, in The Earthscan Reader in Sustainable Agriculture, ed. by Pretty J. CRC Press, Boca Raton, pp. 104-114 (2005).

8 Royal Society of London. Reaping the Benefits: Science and the Sustainable Intensification of Global Agriculture (2009).

9 Nadeem SM, Ahmad M, Zahir ZA, Javaid A and Ashraf M, The role of mycorrhizae and plant growth promoting rhizobacteria (PGPR) in improving crop productivity under stressful environments. Biotechnol Adv 32:429-448 (2014).

10 Baum C, El-Tohamy W and Gruda N, Increasing the productivity and product quality of vegetable crops using arbuscular mycorrhizal fungi: a review. Sci Hortic 187:131-141 (2015).

11 Khan MS, Zaidi A and Musarrat J, Microbes for Legume Improvement. Springer, Vienna (2010).

12 Sindhu SS, Dua S, Verma MK and Khandelwal A, Growth promotion of legumes by inoculation of rhizosphere bacteria, in Microbes for Legume Improvement, ed. by Khan MS, Musarrat J and Zaidi A. Springer, Vienna, pp. 195-235 (2010).

13 Malusà E, Pinzari F and Canfora L, Efficacy of biofertilizers: challenges to improve crop production, in Microbial Inoculants in Sustainable Agricultural Productivity, ed. by Singh DP, Singh HB and Prabha R. Springer, New Delhi, pp. 17-40 (2016).

14 Singh DP, Singh HB and Prabha R eds, Microbial Inoculants in Sustainable Agricultural Productivity. Springer, New York (2016).

15 Timko MP and Singh BB, Cowpea, a multifunctional legume, in Genomics of Tropical Crop Plants, ed. by Moore PH and Ming R. Springer, New York, pp. 227-258 (2008).

16 Gonçalves A, Goufo P, Barros A, Domínguez-Perles R, Trindade H, Rosa EA et al., Cowpea (Vigna unguiculata L. Walp), a renewed multipurpose crop for a more sustainable Agri-food system: nutritional advantages and constraints. J Sci Food Agric 96:2941-2951 (2016).

17 Da Silva AC, da Costa Santos D, Junior DLT, da Silva PB, dos Santos RC and Siviero A, Cowpea: a strategic legume species for Food security and health, in Legume Seed Nutraceutical Research, ed. by Jimenez-Lopez J and Clemente A. IntechOpen, London (2018) Available: https://www.intechopen.com/books/ legume-seed-nutraceutical-research/cowpea-a-strategic-legumespecies-for-food-security-and-health.

18 Andrade MMM, Stamford NP, Santos CER, Freitas ADS, Sousa CA and Junior MAL, Effects of biofertilizer with diazotrophic bacteria and mycorrhizal fungi in soil attribute, cowpea nodulation yield and nutrient uptake in field conditions. Sci Hortic 162:374-379 (2013).

19 Oliveira RS, Carvalho P, Marques G, Ferreira L, Pereira S, Nunes M et al., Improved grain yield of cowpea (Vigna unguiculata) under water deficit after inoculation with Bradyrhizobium elkanii and Rhizophagus irregularis. Crop Pasture Sci 68:1052-1059 (2017).

20 Vosátka M, Látr A, Gianinazzi S and Albrechtová J, Development of arbuscular mycorrhizal biotechnology and industry: current achievements and bottlenecks. Symbiosis 58:29-37 (2012).

21 O'Callaghan M, Microbial inoculation of seed for improved crop performance: issues and opportunities. Appl Microbiol Biotechnol 100:5729-5746 (2016).

22 Ma Y, Látr A, Rocha I, Freitas H, Vosátka M and Oliveira RS, Delivery of inoculum of Rhizophagus irregularis via seed coating in combination with Pseudomonas libanensis for cowpea production. Agronomy 9:33 (2019).

23 Rocha I, Ma Y, Vosátka M, Freitas H and Oliveira RS, Growth and nutrition of cowpea (Vigna unguiculata) under water deficit as influenced by microbial inoculation via seed coating. J Agron Crop Sci 205:447-459 (2019).

24 Colla G, Rouphael Y, Bonini P and Cardarelli M, Coating seeds with endophytic fungi enhances growth, nutrient uptake, yield and grain quality of winter wheat. Int J Plant Prod 9:171 - 190 (2015).

25 Cely MV, de Oliveira AG, de Freitas VF, de Luca MB, Barazetti AR, dos Santos IM et al., Inoculant of arbuscular mycorrhizal fungi (Rhizophagus clarus) increase yield of soybean and cotton under field conditions. Front Microbiol 7:720 (2016).

26 Oliveira RS, Rocha I, Ma Y, Vosátka M and Freitas H, Seed coating with arbuscular mycorrhizal fungi as an ecotechnologicalapproach 
for sustainable agricultural production of common wheat (Triticum aestivum L.). J Toxicol Environ Health Part A 719:329-337 (2016).

27 Rocha I, Ma Y, Carvalho MF, Magalhães C, Janoušková M, Vosátka M et al., Seed coating with inocula of arbuscular mycorrhizal fungi and plant growth promoting rhizobacteria for nutritional enhancement of maize under different fertilization regimes. Arch Agron Soil Sci 65:31-43 (2019).

28 Ryan MH and Graham JH, Little evidence that farmers should consider abundance or diversity of arbuscular mycorrhizal fungi when managing crops. New Phytol 220:1092-1107 (2018).

29 Thirkell TJ, Charters MD, Elliott AJ, Sait SM and Field KJ, Are mycorrhizal fungi our sustainable saviours? Considerations for achieving food security. J Ecol 105:921 -929 (2017).

$30 \mathrm{Ma} \mathrm{Y}$, Rajkumar M, Zhang $\mathrm{C}$ and Freitas $\mathrm{H}$, Inoculation of brassica oxyrrhina with plant growth promoting bacteria for the improvement of heavy metal phytoremediation under drought conditions. J Hazard Mater 320:36-44 (2016).

31 Scott JM, Hill CB and Jessop RS, Growth chamber study of phosphorus applied as drilled granules or as seed coatings to wheat sown in soils differing in P-sorption capacity. Fertil Res 29:281-287 (1991).

32 Porter W, The "most probable number" method for enumerating infective propagules of vesicular arbuscular mycorrhizal fungi in soil. Aust J Soil Res 17:515-519 (1979).

33 Phillips JM and Hayman DS, Improved procedures for clearing and staining parasitic and vesicular-arbuscular mycorrhizal fungi for rapid assessment of infection. Trans BrMycol Soc 55:158-161 (1970).

34 Oliveira RS, Vosátka M, Dodd JC and Castro PM, Studies on the diversity of arbuscular mycorrhizal fungi and the efficacy of two native isolates in a highly alkaline anthropogenic sediment. Mycorrhiza 16:23-31 (2005).

35 Giovannetti $\mathrm{M}$ and Mosse B, An evaluation of techniques for measuring vesicular arbuscular mycorrhizal infection in roots. New Phytol 84:489-500 (1980).

36 Muyzer G, de Waal EC and Uitterlinden AG, Profiling of complex microbial populations by denaturing gradient gel electrophoresis analysis and polymerase chain reaction-amplified genes coding for 16S rRNA. Appl Environ Microb 59:695-700 (1993).

37 Agaras B and Valverde CA, Novel oligonucleotide pair for genotyping members of the Pseudomonas genus by single-round PCR amplification of the gyrB gene. Methods Protoc 1:24 (2018).

38 Dastager SG, Deepa CK and Pandey A, Plant growth promoting potential of Pontibacter niistensis in cowpea (Vigna unguiculata (L.) Walp.). Appl Soil Ecol 49:250-255 (2011).

39 Omirou M, Fasoula DA and loannides IM, Bradyrhizobium inoculation alters indigenous AMF community assemblages and interacts positively with AMF inoculum to improve cowpea performance. Appl Soil Ecol 108:381-389 (2016).

40 Oruru MB, Njeru EM, Pasquet R and Runo S, Response of a wild-type and modern cowpea cultivars to arbuscular mycorrhizal inoculation in sterilized and non-sterilized soil. J Plant Nutr 41:90-101 (2018).

41 Lekberg $\mathrm{Y}$ and Helgason T, In situ mycorrhizal function - knowledge gaps and future directions. New Phytol 220:957-962 (2018).

42 FAOSTAT. Food and Agriculture Organization of the United Nations. FAOSTAT Online Database (2005). Available: http://www.fao.org/faostat/ en/\#data/PP [10 June 2019].

43 Berta G, Copetta A, Gamalero E, Bona E, Cesaro P, Scarafoni A et al., Maize development and grain quality are differentially affected by mycorrhizal fungi and a growth-promoting pseudomonad in the field. Mycorrhiza 24:161 - 170 (2014).
44 Hernández JLG, Hernández-Montiel LG, Zulueta-Rodríguez R, Cordoba-Matson MV, Ortega-García J, Murillo-Amador B et al., in Effect by Plant Growth Promoting Bacteria (Azospirillum halopraeferens and Klebsiella pneumoniae) on Lipid Value in Seed of the Halophyte Salicornia bigelovii Torr in Sabkha Ecosystems, ed. by Khan M, Boër B, Özturk M, Clüsener-Godt M, Gul B and Breckle SW. Springer, Cham, pp. 397-403 (2016).

45 Bona E, Cantamessa S, Massa N, Manassero P, Marsano F, Copetta A et al., Arbuscular mycorrhizal fungi and plant growth-promoting pseudomonads improve yield, quality and nutritional value of tomato: a field study. Mycorrhiza 27:1 -11 (2017).

46 Wu QS, Xia RX and Zou YN, Improved soil structure and citrus growth after inoculation with three arbuscular mycorrhizal fungi under drought stress. Europ J Soil Biol 44:122-128 (2008).

47 Oliveira RS, Castro PML, Dodd JC and Vosátka M, Synergistic effect of Glomus intraradices and Frankia spp. on the growth and stress recovery of Alnus glutinosa in an alkaline anthropogenic sediment. Chemosphere 60:1462-1470 (2005).

48 Lehmann A, Veresoglou SD, Leifheit EF and Rillig MC, Arbuscular mycorrhizal influence on zinc nutrition in crop plants e a meta-analysis. Soil Biol Biochem 69:123-131 (2014).

49 Lehmann A and Rillig MC, Arbuscular mycorrhizal contribution to copper, manganese and iron nutrient concentrations in crops-a meta-analysis. Soil Biol Biochem 81:147-158 (2015).

50 Lehmann J and Kleber $M$, The contentious nature of soil organic matter. Nature 528:60-68 (2015).

51 Marulanda A, Barea JM and Azcón R, Stimulation of plant growth and drought tolerance by native microorganisms (AM fungi and bacteria) from dry environments. Mechanisms related to bacterial effectiveness. J Plant Growth Regul 28:115-124 (2009).

52 Koch AM, Antunes PM, Barto EK, Cipollini D, Mummey DL and Klironomos JN, The effects of arbuscular mycorrhizal (AM) fungal and garlic mustard introductions on native AM fungal diversity. Biol Invasions 13:1627-1639 (2011).

53 Knegt B, Jansa J, Franken O, Engelmoer DJ, Werner GD, Bücking $\mathrm{H}$ et al., Host plant quality mediates competition between arbuscular mycorrhizal fungi. Fungal Ecol 20:233-240 (2016).

54 Pearson JN, Abbott LK and Jasper DA, Mediation of competition between colonizing VA mycorrhizal fungi by the host plant. New Phytol 123:93-98 (1993).

55 Werner GD and Kiers ET, Order of arrival structures arbuscular mycorrhizal colonization of plants. New Phytol 205:1515-1524 (2015).

56 Bever JD, Richardson SC, Lawrence BM, Holmes J and Watson M, Preferential allocation to beneficial symbiont with spatial structure maintains mycorrhizal mutualism. Ecol Lett 12:13-21 (2009).

57 Janoušková $M$, Krak K, Vosátka M, Püschel D and Štorchová H, Inoculation effects on root-colonizing arbuscular mycorrhizal fungal communities spread beyond directly inoculated plants. PLoS One 12:e0181525 (2017).

58 Haas D and Défago G, Biological control of soil-borne pathogens by fluorescent pseudomonads. Nat Rev Microbiol 3:307-331 (2005).

59 Landa BB, Mavrodi DM, Thomashow LS and Weller DM, Interactions between strains of 2,4-diacetylphloroglucinol-producing Pseudomonas fluorescens in the rhizosphere of wheat. Phytopathology 93:982-994 (2003).

60 Rosas SB, Avanzini G, Carlier E, Pasluosta C, Pastor N and Rovera M, Root colonization and growth promotion of wheat and maize by Pseudomonas aurantiaca SR1. Soil Biol Biochem 41:1802-1806 (2009). 